\title{
VARIATIONS IN THE STRUCTURAL CHARACTER AND STABILITY OF THE NUCLEAR CHROMATIN IN MORPHOLOGICALLY NORMAL HUMAN SPERMATOZOA
}

\author{
J. M. BEDFORD, ${ }^{*}$ M. J. BENT AND H. CALVIN \\ Departments of Anatomy, Human Genetics and International Institute of Human \\ Reproduction, Columbia University College of Physicians and Surgeons, New York, \\ N.Y. 10032, U.S.A.
}

(Received 11th February 1972)

Summary. Decondensation of the nuclear chromatin of mammalian spermatozoa can be induced by treatment with sodium dodecyl sulphate (SDS) containing dithiothreitol (DTT) - a reagent which specifically cleaves -S-S- crosslinks. The nuclei of mature rabbit and monkey spermatozoa respond to SDS/DTT treatment in a uniform manner, each expanding to a similar degree, whereas those of the treated human ejaculate display a consistent heterogeneity between individual spermatozoa in their degree of decondensation which is unrelated to head shape.

A variable proportion of the sperm nuclei from human ejaculates will swell in SDS alone and correlated ultrastructural studies indicate that these probably possess incompletely condensed chromatin of granular appearance. The heterogeneity of sperm nuclei in the human ejaculate revealed by combined treatment with SDS/DTT, on the other hand, is probably not visible at the ultrastructural level before such treatment. The decondensation induced by SDS/DTT allows detection of nuclear vacuoles which are not evident with the light microscope in intact spermatozoa. Such vacuoles were present in $>90 \%$ of the spermatozoa of one individual whose ejaculate was otherwise normal.

The finding that human sperm nuclei of normal shape may vary considerably with respect to the character of their chromatin raises several questions; these include the aetiology and molecular basis of such heterogeneity and the possible bearing these differences might have on the early development of the human embryo.

The present technique of controlled nuclear decondensation provides a simple method by which the structural quality of sperm nuclei can be assessed.

\section{INTRODUCTION}

During the latter stages of spermiogenesis, the spermatid nucleus becomes

* Present address: Department of Obstetrics and Gynecology, Cornell University Medical Gollege, 1300 York Avenue, New York, N.Y. 10021, U.S.A. 
highly condensed and adopts the elongated form characteristic of the species. Although we have little understanding of the forces which determine the shape of the nucleus (Fawcett, Anderson \& Phillips, 1971), it is known that these visible modifications are accompanied by biochemical changes involving elimination of RNA from the nucleus at the beginning of nuclear elongation (Monesi, 1971) and replacement of lysine-rich histone by a more basic argininerich protein (Alfert, 1956; Monesi, 1965; Gledhill, Gledhill, Rigler \& Ringertz, 1966a; Vaughn, 1966; Kopecny, 1970). In eutherian mammals, there is also a coincident incorporation of cysteine (Loir, 1970) which finally constitutes about $13 \%$ of the amino acid residues in the protein of the nuclear chromatin (bull-Coelingh, Rozijn \& Monfoort, 1969; rat-H. Calvin, unpublished observations). The resistant keratinoid quality of the nucleus of eutherian spermatozoa is very probably determined by $-\mathrm{S}-\mathrm{S}$ - crosslinks formed between thiol groups of adjacent protein chains within the chromatin. Although the nuclei of spermatozoa in the rete testis or caput epididymidis contain chromatin which appears uniformly condensed, evidently the nuclei of such spermatozoa are structurally immature, for it is only during passage of spermatozoa through the epididymis that the majority of the covalent -S-S- crosslinks are established within the chromatin. This statement is based on the finding that when treated with sodium dodecyl sulphate (SDS) containing dithiothreitol (DTT) (Cleland's reagent), which specifically cleaves disulphide bonds, the nuclei of spermatozoa in the caput epididymidis consistently swell at a much faster rate and more irregularly than those of mature spermatozoa (Calvin \& Bedford, 1971). This appears to be the case in all of ten species of eutheria examined, including man.

Although the nuclei of mature spermatozoa of all other eutherian mammals generally behave uniformly in SDS/DTT, each swelling at a similar rate within a population, our initial observations suggested that this is not true of human spermatozoa from the cauda of the epididymis or from the ejaculate. These respond in a variety of ways to this treatment; within a sample, some nuclei swell rapidly while others exhibit minimal or no swelling within the same time period. Although the implications of such variation between nuclei are not known, their possible relationship to the fertility and/or genetic competence of human spermatozoa seemed to justify their further study. The results in this present report indicate that considerable structural heterogeneity unrelated to any obvious variation in the shape of the nucleus is a consistent characteristic of spermatozoa in the ejaculates of men in this society.

\section{MATERIALS AND METHODS}

Ejaculated samples of human spermatozoa, obtained by masturbation, were provided by forty-four medical or dental students 22 to 30 years old. Samples from other species for comparison were collected with an artificial vagina (rabbit), or directly from the vas deferens (monkey). After each specimen had been routinely assessed for concentration, motility and morphology, one drop of semen was mixed with nine drops of $1 \% \mathrm{SDS}$ in $0.05 \mathrm{~m}$-sodium borate $(\mathrm{pH}$ $9 \cdot 0)$, with or without DTT at a concentration of $0.31 \mathrm{mg} / \mathrm{ml}$. 
The reaction of the spermatozoa in SDS/DTT was allowed to proceed at room temperature $\left(23\right.$ to $25^{\circ} \mathrm{C}$ ), and was stopped after 15,30 or $60 \mathrm{~min}$ (SDS/DTT), or after 60 mins (SDS alone), by addition of an equal volume of $2.5 \%$ glutaraldehyde in sodium borate buffer. Assessment of the reaction to SDS/DTT was made simply by examining a drop of the reaction mixture with a phase contrast microscope. The spermatozoa were assessed (>200/sample) according to the degree of nuclear decondensation, being classified as 'unchanged', 'moderately swollen' or 'grossly swollen' (Pl. 1, Figs 1 and 2). This assessment was necessarily subjective but was always performed by the same operator (M.J.B.). The designation 'unchanged' implies no change in outline or in density, the nucleus remaining refractile (U in Pl. 1, Figs 1 and 2); 'moderately swollen' implies some enlargement and darkening of the nucleus together with loss of its refractile quality (M in Pl. I, Figs 1 and 2); 'grossly swollen' refers to the type of nucleus which had become greatly enlarged with loss of its density, as seen with phase contrast optics ( $\mathrm{S}$ in Pl. 1, Figs 1 and 2).

For electron microscopy, untreated or experimental sperm samples were centrifuged at $2000 \mathrm{~g}$ for $20 \mathrm{~min}$ and the pellet was then fixed in $2.5 \%$ glutaraldehyde in $0.05 \mathrm{M}$-sodium borate buffer. After $1 \mathrm{hr}$, the pellet was post-fixed in $1 \%$ osmium tetroxide and following dehydration in alcohols $(30 \%$ to $100 \%)$ and propylene oxide, it was embedded in Epon 812. Thin sections stained with uranyl acetate and lead citrate were examined in a Phillips (200) electron microscope.

\section{RESULTS}

When exposed to SDS/DTT for 15 to $45 \mathrm{~min}$, the nuclei of spermatozoa from the ejaculate of the rabbit, or the vas deferens of the capuchin and rhesus monkeys, underwent decondensation in a regular, uniform manner (Pl. 1, Fig. 3 and Pl. 2, Fig. 4), there being essentially no within-sample difference between cells in the rate of nuclear swelling. The structural homogeneity of the nuclei of mature spermatozoa in these species stands in marked contrast to the consistent nuclear heterogeneity of spermatozoa in ejaculates obtained from forty-four healthy young men (Table 1). While the quality of the majority of ejaculates from the human donors was within the accepted normal range as judged by their motility, concentration and morphology, a structural heterogeneity of the nuclei of different spermatozoa was evident in every ejaculate tested, as judged by their expansion in SDS/DTT (Pl. 1, Figs. 1 and 2, and Pl. 2, Fig. 5). In those samples which showed a low concentration (Nos 2, 14, 31, 36 and 5) or low motility (Nos 21, 23, 42 and 44), there was no close relationship between these parameters and the structural quality of the sperm nuclei.

On the basis of the response at 15 and $30 \mathrm{~min}$, it is apparent that in addition to the differences between cells within one sample, there was considerable variation between samples in the rate at which nuclear swelling occurred when exposed to SDS/DTT under standard conditions (Table 1). For example, only $7 \%$ of the nuclei remained 'unchanged' in Sample 5 after 15 min exposure, in contrast to $80.5 \%$ in Sample 18. Over a period of several weeks, the spermatozoa from the donors maintained this characteristic reactivity to SDS/DTT in 
several successive ejaculates (e.g. No. 3 versus No. 38). This difference was not always maintained when these same individuals were retested after a lapse of 5 months.

Although the differences observed in the rate and degree of nuclear decondensation in SDS/DTT probably reflect variation in the structural character of the chromatin, the overall rate of the reaction can also be affected significantly by the seminal plasma present in the reaction mixture. Comparison of the swelling-rate of the nuclei of spermatozoa in seminal plasma with that of washed aliquots shows that substances in the contaminating seminal plasma can readily depress the rate of the nuclear swelling reaction. The nuclei of ejaculated spermatozoa suspended in Tyrode's solution always expand more rapidly, when mixed with SDS/DTT, than those in seminal plasma.

Careful observations of the decondensation of the nuclei of human spermatozoa in SDS/DTT make it clear that differences in the rate of expansion within a sample are not related to, nor do they depend on there being a difference in head shape. This point is reinforced by observations with the electron microscope made on thin sections of ejaculated spermatozoa. Whereas little variation was apparent in the nuclear chromatin of individual spermatozoa in

\section{EXPLANATION OF PLATES 1 TO 4}

PLATE 1

Figs 1 and 2. Spermatozoa of donors No. 38 (Fig. 1) and No. 36 (Fig. 2) fixed in glutaraldehyde after $30 \mathrm{~min}$ exposure to SDS/DTT. The sperm nuclei have expanded to a variable degree; some have not changed (U), while others have become moderately swollen $(\mathbf{M})$ or grossly swollen $(\mathbf{S})$ in the same environment. Phase contrast. $\times 600$.

Fig. 3. Spermatozoa from the vas deferens of the rhesus monkey. The condensed spermatozoa (inset) were exposed to SDS/DTT for only $5 \mathrm{~min}$ and are hardly changed, whereas in the main figure, spermatozoa exposed for $20 \mathrm{~min}$ to SDS/DTT have all swollen in a uniform manner. Phase contrast. $\times 600$.

PLATE 2

FIG. 4. Thin section of the nuclei of ejaculated rabbit spermatozoa exposed to SDS/DTT for $40 \mathrm{~min}$. Note the homogeneous swelling response, typical of spermatozoa in this species; this contrasts with the heterogeneous response of ejaculated human spermatozoa in Fig. 5, which were treated and prepared in a similar manner. $\times 10,000$.

Fig. 5. Thin section of the nuclei of ejaculated spermatozoa in one sample from donor No. 38 ; these were treated with SDS/DT T for $15 \mathrm{~min}$ before fixation. Note the variation in the extent of decondensation from one nucleus to another. $T$ : sheath of the tail main-piece. $\mathrm{F}$ : outer dense fibres of the sperm tail. $\times 12,000$.

\section{PLATE 3}

Fig. 6. Thin section of a human sperm head in the lumen of the seminiferous tubule immediately following spermiation. Visible condensation of the nucleus is normally completed before spermiation and in this case, the dense appearance of the chromatin interspersed by small vacuoles is representative of the normal nucleus of spermatozoa in all segments of the epididymis as well as those in the ejaculate. $\times 46,000$.

Fig. 7. Thin section of an untreated head of normally shaped human spermatozoon in the ejaculate. In contrast to the nucleus of normal appearance in Fig. 6, such abnormal nuclei display different degrees of a mosaic or granular texture which denotes incomplete condensation of the chromatin. $\times 46,000$.

\section{PLATE 4}

Fig. 8. More extreme example of incomplete condensation, as noted in Pl. 3, Fig. 7.

FIGs 9 and 10. Phase microscope pictures of sperm heads in an ejaculate from donor No. 16. In Fig. 9, partial swelling of the nuclei after treatment with SDS/DTT for $15 \mathrm{~min}$ has already revealed the presence of vacuoles $(V)$ in almost every sperm head. These vacuoles are more evident in the sample in Fig. 10 in which the decondensed heads were treated for a longer period of $30 \mathrm{~min} . \times 600$. 
PIATE 1
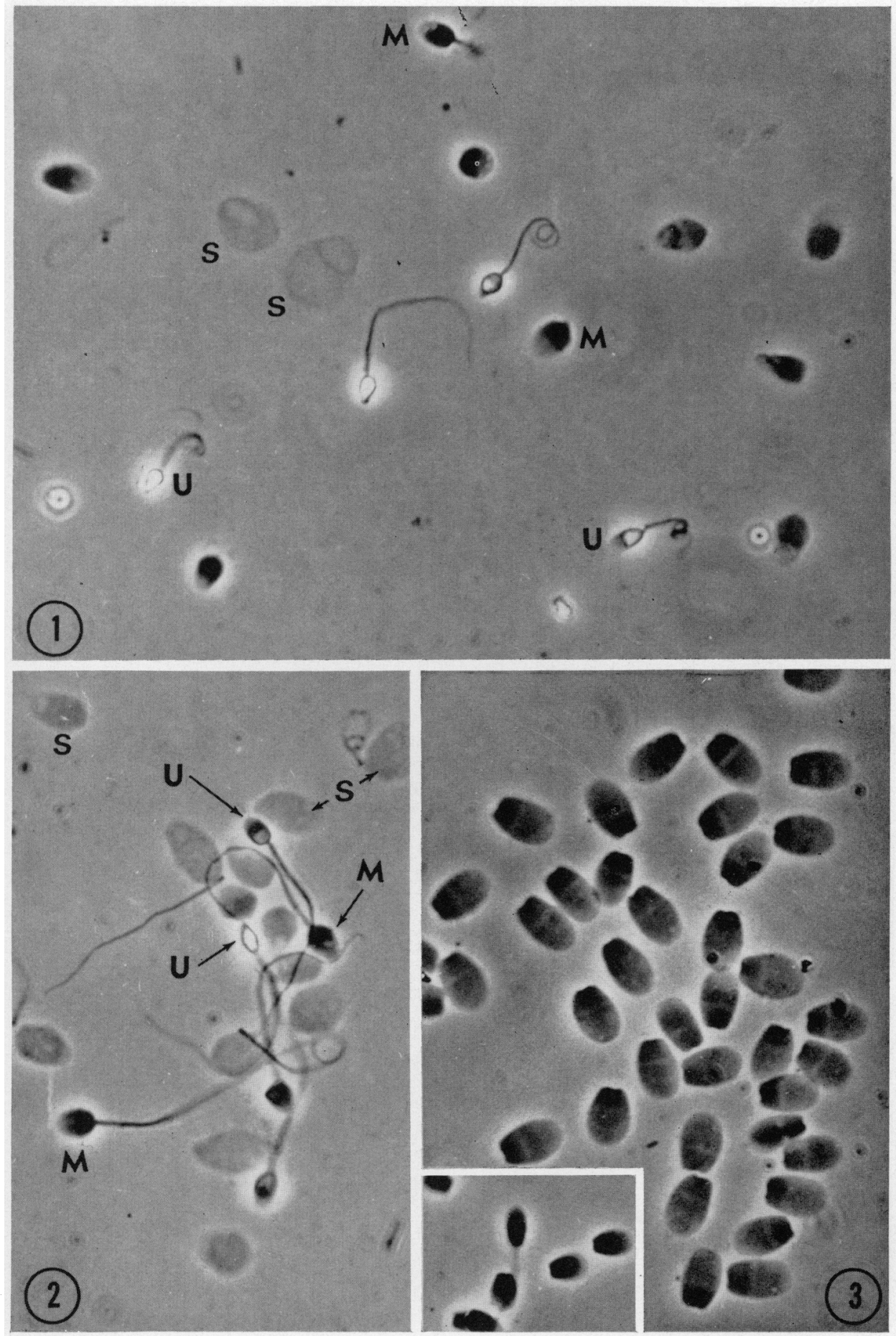

(Facing p. 22) 
PLATE 2
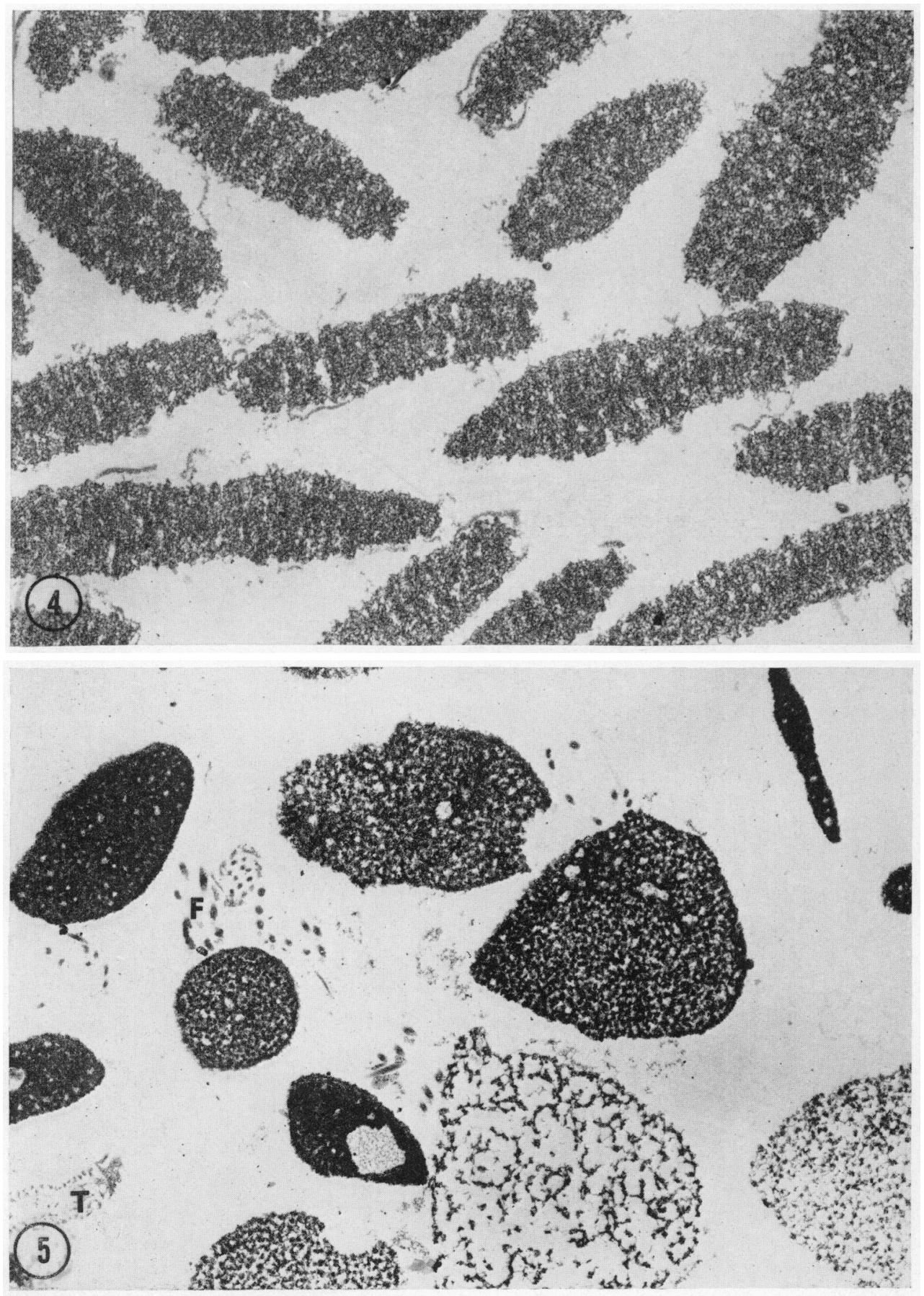

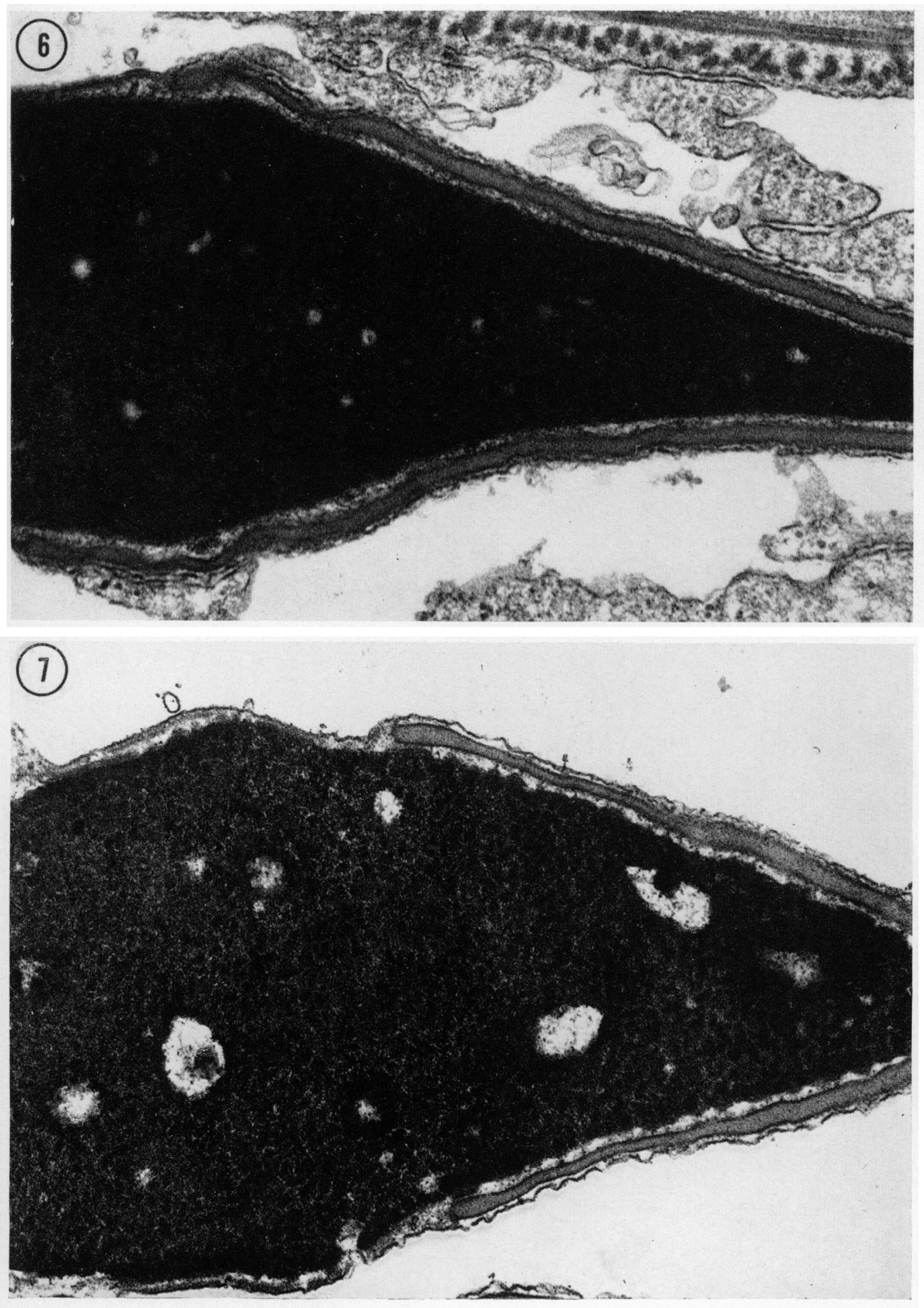
PLATF, 4
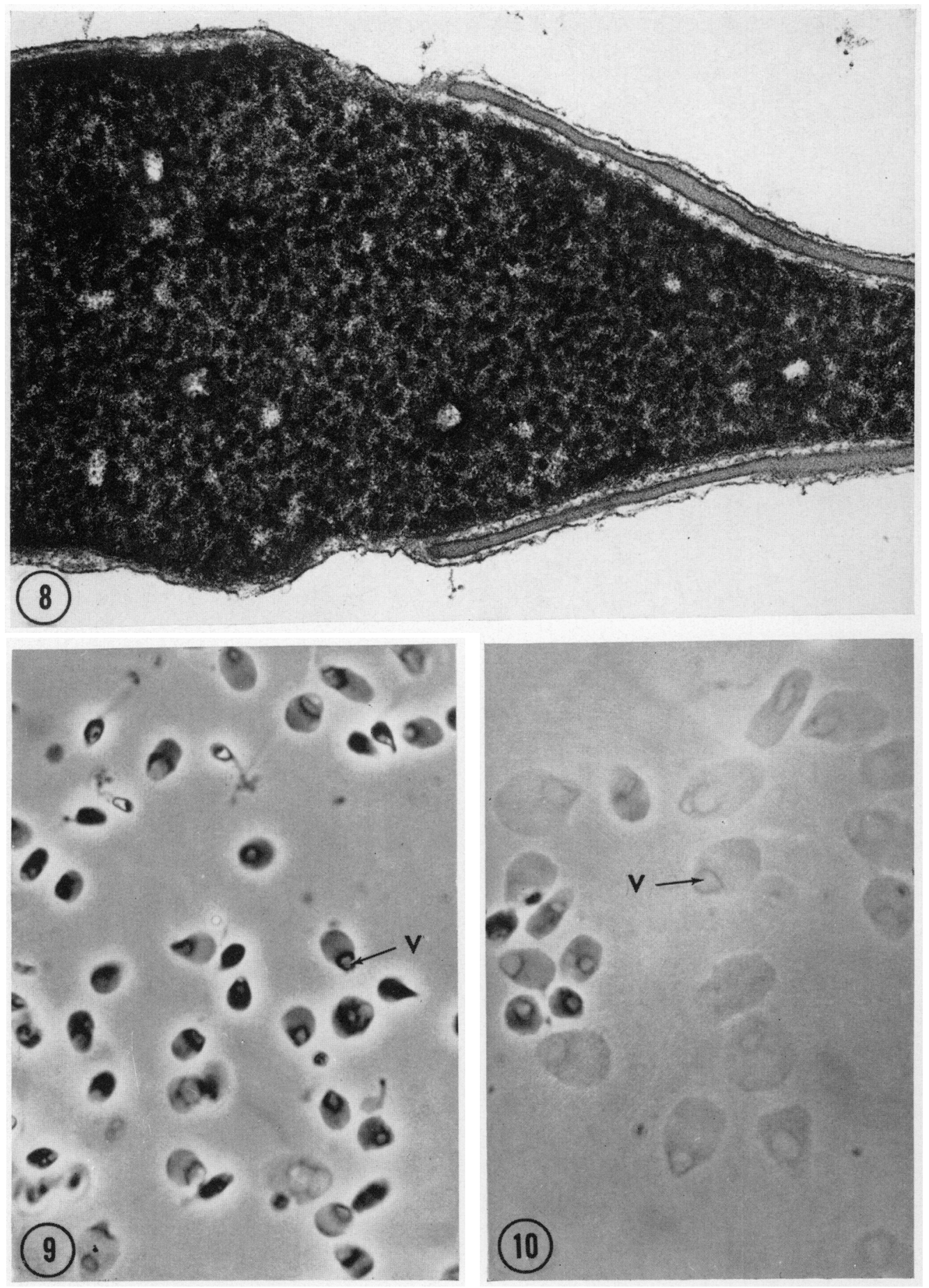

(Facing p. 23) 
Table 1. Response of the nuclei of ejaculated spermatozoa to SDS/DTT, and SDS alone, in a random population of men

\begin{tabular}{|c|c|c|c|c|c|c|c|c|c|}
\hline \multirow{2}{*}{$\begin{array}{c}\text { Donor } \\
\text { no. }\end{array}$} & \multirow{2}{*}{$\begin{array}{l}\text { Sperm conc. } \\
\left(\times 10^{6} / \mathrm{ml}\right)\end{array}$} & \multirow{2}{*}{$\begin{array}{c}\% \\
\text { motility }\end{array}$} & \multicolumn{3}{|c|}{$S D S / D T T: 15 \min (\%)$} & \multicolumn{3}{|c|}{$S D S \mid D T T: 30 \min (\%)$} & \multirow{2}{*}{$\begin{array}{l}\text { SDS alone for } \\
60 \text { min }(\% \\
\text { nuclei moderately } \\
\text { and grossly } \\
\text { swollen) }\end{array}$} \\
\hline & & & $\begin{array}{l}\text { Unchanged } \\
(U)\end{array}$ & $\begin{array}{c}\text { Moderately } \\
\text { swollen } \\
(M)\end{array}$ & $\begin{array}{l}\text { Grossly } \\
\text { swollen } \\
(S)\end{array}$ & $\begin{array}{l}\text { Unchanged } \\
(I I)\end{array}$ & $\begin{array}{l}\text { Moderately } \\
\text { swollen } \\
(M)\end{array}$ & $\begin{array}{l}\text { Grossly } \\
\text { swollen } \\
(S)\end{array}$ & \\
\hline $\begin{array}{r}1 \\
2 \\
3 \\
4 \\
5 \\
6 \\
7 \\
8 \\
9 \\
10 \\
11 \\
12 \\
13 \\
14 \\
15 \\
16 \\
17 \\
18 \\
19 \\
20 \\
21 \\
22 \\
23 \\
24 \\
25 \\
26 \\
27 \\
28 \\
29 \\
30 \\
31 \\
32 \\
33 \\
34 \\
35 \\
36 \\
37 \\
38 \\
39 \\
40 \\
41 \\
42 \\
43 \\
44\end{array}$ & $\begin{array}{c}96 \\
16 \cdot 5 \\
30 \\
50 \cdot 5 \\
67 \cdot 5 \\
32 \cdot 5 \\
90 \\
38 \cdot 5 \\
104 \\
96 \\
47 \\
24 \\
113 \\
22 \\
59 \\
27 \cdot 5 \\
120 \\
123 \\
64 \\
35 \\
94 \\
98 \\
73 \\
34 \cdot 5 \\
179 \\
77 \\
21 \\
76 \\
65 \\
150 \\
21 \\
41 \cdot 5 \\
205 \\
57 \cdot 5 \\
129 \\
17 \\
93 \\
145 \\
77 \\
68 \\
152 \\
36 \cdot 5 \\
5 \\
183\end{array}$ & $\begin{array}{l}73 \\
70 \\
72 \\
44 \\
59 \\
42 \\
29 \\
66 \\
85 \\
57 \\
49 \\
76 \\
74 \\
80 \\
69 \\
56 \\
93 \\
93 \\
79 \\
71 \\
29 \\
67 \\
28 \\
68 \\
72 \\
60 \\
77 \\
59 \\
64 \\
39 \\
40 \\
50 \\
68 \\
62 \\
50 \\
25 \\
49 \\
61 \\
80 \\
80 \\
49 \\
36 \\
48 \\
15\end{array}$ & $\begin{array}{c}56 \cdot 5 \\
64 \cdot 8 \\
16 \cdot 9 \\
15 \cdot 5 \\
7 \\
5 \\
3 \\
29 \\
30 \cdot 5 \\
57 \\
23 \\
43 \\
68 \\
46 \\
60 \\
35 \cdot 5 \\
84 \\
80 \cdot 5 \\
45 \cdot 5 \\
65 \\
74 \cdot 5 \\
14 \cdot 3 \\
29 \cdot 5 \\
34 \\
48 \cdot 3 \\
46 \cdot 2 \\
21 \cdot 7 \\
28 \cdot 2 \\
8 \cdot 6 \\
28 \cdot 2 \\
24 \cdot 9 \\
5 \cdot 4 \\
42 \cdot 7 \\
23 \cdot 9 \\
8 \cdot 7 \\
35 \cdot 4 \\
49 \cdot 5 \\
69 \cdot 8 \\
34 \\
70 \\
83 \\
15 \\
64 \\
68 \cdot 5\end{array}$ & $\begin{array}{l}34 \\
24 \cdot 9 \\
49 \cdot 3 \\
24 \\
46 \cdot 5 \\
20 \cdot 5 \\
37 \cdot 5 \\
45 \cdot 5 \\
46 \cdot 5 \\
36 \cdot 5 \\
45 \cdot 5 \\
48 \cdot 5 \\
27 \cdot 5 \\
37 \cdot 5 \\
26 \\
31 \cdot 5 \\
13 \\
17 \cdot 5 \\
34 \cdot 5 \\
28 \cdot 5 \\
20 \\
43 \cdot 3 \\
44 \\
40 \cdot 8 \\
34 \cdot 3 \\
28 \cdot 7 \\
43 \cdot 3 \\
39 \cdot 5 \\
48 \cdot 3 \\
34 \cdot 8 \\
36 \cdot 8 \\
23 \cdot 8 \\
34 \\
43 \\
23 \cdot 4 \\
36 \cdot 3 \\
33 \cdot 2 \\
18 \cdot 9 \\
41 \\
23 \\
13 \cdot 5 \\
50 \\
23 \\
21\end{array}$ & $\begin{array}{c}9 \cdot 5 \\
10 \cdot 3 \\
33 \cdot 8 \\
60 \cdot 5 \\
46 \cdot 5 \\
74 \cdot 5 \\
59 \cdot 5 \\
25 \cdot 5 \\
23 \\
6 \cdot 5 \\
31 \cdot 5 \\
8 \cdot 5 \\
4 \cdot 5 \\
16 \cdot 5 \\
14 \\
33 \\
3 \\
2 \\
20 \\
5 \cdot 5 \\
5 \cdot 5 \\
42 \cdot 4 \\
26 \cdot 5 \\
25 \cdot 2 \\
17 \cdot 4 \\
25 \cdot 1 \\
35 \\
32 \cdot 3 \\
43 \cdot 1 \\
37 \\
38 \cdot 3 \\
70 \cdot 8 \\
23 \cdot 3 \\
33 \cdot 1 \\
67 \cdot 9 \\
28 \cdot 3 \\
17 \cdot 3 \\
11 \cdot 3 \\
25 \\
7 \\
3 \cdot 5 \\
35 \\
13 \\
10 \cdot 5\end{array}$ & $\begin{array}{c}3 \cdot 5 \\
9 \cdot 3 \\
0 \\
1 \cdot 5 \\
1 \cdot 5 \\
35 \\
2 \cdot 5 \\
5 \\
1 \\
4 \\
3 \cdot 5 \\
1 \cdot 5 \\
21 \cdot 5 \\
12 \\
42 \\
9 \cdot 5 \\
36 \cdot 5 \\
12 \\
3 \cdot 5 \\
3 \\
52 \cdot 5 \\
1 \cdot 8 \\
8 \\
2 \cdot 2 \\
4 \cdot 8 \\
2 \cdot 3 \\
3 \cdot 3 \\
0 \cdot 5 \\
0 \cdot 5 \\
13 \\
6 \cdot 2 \\
0 \cdot 5 \\
4 \cdot 6 \\
11 \cdot 8 \\
0 \\
9 \cdot 1 \\
4 \cdot 5 \\
50 \cdot 7 \\
1 \cdot 5 \\
36 \cdot 5 \\
47 \cdot 5 \\
3 \\
14 \\
5\end{array}$ & $\begin{array}{c}37 \\
50 \cdot 2 \\
14 \\
12 \cdot 4 \\
6 \cdot 5 \\
9 \cdot 5 \\
3 \\
23 \\
24 \\
32 \\
9 \cdot 5 \\
21 \cdot 5 \\
55 \\
32 \\
28 \\
26 \\
51 \\
59 \cdot 5 \\
30 \\
36 \cdot 5 \\
33 \cdot 5 \\
11 \cdot 9 \\
24 \cdot 5 \\
30 \cdot 5 \\
33 \cdot 9 \\
30 \cdot 7 \\
10 \cdot 3 \\
19 \cdot 9 \\
4 \cdot 2 \\
27 \cdot 8 \\
18 \cdot 6 \\
9 \cdot 8 \\
25 \cdot 2 \\
25 \\
7 \cdot 9 \\
23 \cdot 3 \\
40 \cdot 1 \\
31 \cdot 5 \\
17 \\
39 \\
33 \\
9 \\
49 \\
22\end{array}$ & $\begin{array}{l}59 \cdot 5 \\
40 \cdot 5 \\
86 \\
86 \cdot 1 \\
92 \\
87 \\
94 \cdot 5 \\
72 \\
75 \\
64 \\
87 \\
77 \\
23 \cdot 5 \\
56 \\
30 \\
64 \cdot 5 \\
12 \cdot 5 \\
28 \cdot 5 \\
66 \cdot 5 \\
60 \cdot 5 \\
14 \\
86 \cdot 3 \\
67 \cdot 5 \\
67 \cdot 3 \\
61 \cdot 3 \\
67 \\
86 \cdot 4 \\
79 \cdot 6 \\
95 \cdot 3 \\
59 \cdot 2 \\
75 \cdot 2 \\
89 \cdot 7 \\
70 \cdot 2 \\
63 \cdot 2 \\
92 \cdot 1 \\
67 \cdot 6 \\
55 \cdot 4 \\
17 \cdot 8 \\
81 \cdot 5 \\
24 \cdot 5 \\
19 \cdot 5 \\
88 \\
37 \\
73\end{array}$ & $\begin{array}{c}7 \\
8 \cdot 6 \\
7 \cdot 6 \\
39 \cdot 5 \\
12 \cdot 4 \\
16 \\
19 \cdot 5 \\
29 \cdot 5 \\
19 \\
8 \\
26 \\
2 \\
6 \\
14 \cdot 5 \\
12 \\
28 \cdot 5 \\
4 \\
6 \cdot 5 \\
9 \\
7 \\
8 \\
29 \cdot 9 \\
13 \cdot 5 \\
27 \\
18 \cdot 4 \\
26 \\
23 \cdot 4 \\
21 \cdot 9 \\
21 \cdot 5 \\
32 \cdot 9 \\
37 \cdot 5 \\
30 \\
27 \\
13 \cdot 3 \\
9 \cdot 2 \\
5 \\
12 \\
8 \\
20 \cdot 5 \\
10 \cdot 5 \\
10 \\
17 \\
11 \cdot 5 \\
5\end{array}$ \\
\hline Means & & & $40 \cdot 1$ & $33 \cdot 5$ & $26 \cdot 4$ & $10 \cdot 5$ & $25 \cdot 9$ & $63 \cdot 6$ & $16 \cdot 4$ \\
\hline
\end{tabular}

All nuclei were grossly swollen after exposure to SDS/DTT for $60 \mathrm{~min}$. 
the ejaculates of laboratory and domestic animals, distinct ultrastructural differences in the texture of the nucleus were seen in many of the spermatozoa in the human ejaculate. The chromatin of human sperm nuclei varied in texture from a moderately dense homogeneous type, which is seen most commonly (Pl. 3, Fig. 6), through a series which exhibits increasing granularity (Pl. 3, Fig. 7 and Pl. 4, Fig. 8). This coarse texture is indicative of incomplete condensation of the sperm nucleus; yet such nuclei may often appear quite normal in shape and would not be detected as abnormal by simple observation with the light microscope. It is likely, however, that a real correlation exists between the distinctly granular nucleus as seen in the electron microscope (Pl. 3, Fig. 7 and Pl. 4, Fig. 8) and the spermatozoa which swell in SDS alone. In two of the several ejaculates examined at random from the infertility clinic of this medical centre, approximately 50 to $60 \%$ of the sperm nuclei expanded significantly in SDS alone, a percentage outside the range seen in the normal donor population (Table 1). Examination of these samples with the electron microscope revealed a similar percentage of the spermatozoa with a distinct granularity of the chromatin of the quality shown here in Pl. 3, Fig. 7 and Pl. 4, Fig. 8.

We have reported previously that sperm tail structures also become stabilized by $-\mathrm{S}-\mathrm{S}-$ crosslinks during epididymal passage (Calvin \& Bedford, 1971). In the present study, there was usually a correlation between the persistence of the tail and the 'tightness' of the nucleus (Pl. 1, Figs 1 and 2), but this was not invariable and, in some cases, the tail was retained when the nucleus had undergone a distinct degree of decondensation.

Vacuoles occur commonly in human sperm nuclei (see Fawcett, 1958), but generally these can be observed only with the electron microscope. The nuclear swelling technique described in this study allows recognition of such vacuoles with the phase contrast microscope after decondensation has occurred. The most striking example of this condition occurred in the spermatozoa from donor No. 16 , in which more than $90 \%$ of the nuclei displayed very distinct vacuolization (Pl. 4, Figs 9 and 10) and this was confirmed with the electron microscope. This characteristic was maintained to the same degree in an ejaculate obtained 3 weeks later. It is noteworthy that the presence of such vacuoles was not accompanied by any other unusual structural quality of the sperm nuclei, as revealed by their reaction to SDS/DTT.

\section{DISGUSSION}

Much has been written about the analysis of human semen (see Freund, 1968; Eliasson, 1971) and it has long been appreciated that from a morphological standpoint, the population of spermatozoa ejaculated by normal fertile men compares poorly with that of fertile males in domestic and laboratory species. The common variations of head shape (large, small, tapering, etc.), their prevalence and their constancy in samples from a given individual have been described thoroughly, though the interpretation of these parameters appears to vary in different laboratories (Freund, 1966). However, there is at present no easy way to judge the state of the sperm nucleus other than by its shape.

Two main points emerge from the present study. Firstly, it is clear that the 
ejaculates of men in this society contain many spermatozoa which present a 'normal' morphology, but show marked differences in the structural character of their nuclear chromatin. Thus, the presence of an oval uniform head (type 1-oval (normal) of MacLeod, 1964, 1970) cannot necessarily be presumed to indicate a normally formed nucleus. Furthermore, this variation in the structural quality of the human sperm nucleus stands in very real contrast to the homogeneity observed in samples of mature spermatozoa from monkeys and rabbits.

The second point concerns a more extreme deviation, which is reflected in the coarse ultrastructural texture of the nucleus in a generally small though variable proportion of normally shaped spermatozoa. We believe that those nuclei which exhibit such distinct granularity (PI. 3, Fig. 7 and Pl. 4, Fig. 8) have failed to undergo normal condensation, and since this process is usually completed before spermiation (Fawcett \& Burgos, 1956, and Pl. 3, Fig. 6), the root cause of this type of defect must lie at the testicular level. Normal mature sperm nuclei do not change in SDS solution, but in fifty-one semen samples chosen at random from the infertility clinic of this centre, seven ejaculates have been identified in which more than $40 \%$ of the sperm nuclei swelled distinctly in SDS alone, and in two of these, the swelling rate lay between 50 and $60 \%$; this contrasts with the mean results from the student donor population in which only $16 \%$ of the nuclei showed a similar reaction (Table 1). Parallel studies of such samples with the electron microscope reveal a similarity in the proportion of spermatozoa which display a distinct granularity or mosaic appearance of the chromatin at the ultrastructural level, and those which exhibit a degree of visible swelling when exposed to SDS alone. It seems likely, therefore, that signs of immaturity or pathology of the sperm nucleus which are visible at the ultrastructural level will be manifested by a swelling response when exposed to SDS solution. The use of this approach with the phase contrast microscope may well obviate the need for electron microscopy in routine or initial evaluation of the type of infertile condition described by McCosker (1969) in the bull, where ultrastructural studies revealed a similar granularity as a reflection of nuclear pathology.

The treatment of spermatozoa with SDS/DTT may bring to light other nuclear defects not obvious in untreated samples. In this respect, we allude to donor No. 16, normal by all other standards, whose ejaculate revealed large nuclear vacuoles in a majority of spermatozoa after partial decondensation (Pl. 4, Figs 9 and 10). These vacuoles, observed in a second ejaculate and confirmed in untreated aliquots by electron microscopy, did not seem to affect the response of the nucleus to SDS/DTT. It is not known whether such vacuoles may affect the functional integrity of the spermatozoa.

By contrast with the granular nuclei in which a swelling response is evoked by SDS alone, the nuclear heterogeneity revealed only by the additional presence of DTT probably reflects more subtle differences in the quality of the chromatin, which are not detectable by simple electron microscopic examination. These may be related to the significant change in the structural quality of the nucleus during epididymal passage, engendered by establishment of -S-S- crosslinks in the chromatin, which also is not apparent at the ultrastructural level (Calvin 
\& Bedford, 1971). Since mature spermatozoa of other mammals generally do not display nuclear heterogeneity in response to treatment with SDS or SDS/DTT (Pl. 1, Fig. 3 and PI. 2, Fig. 4), this raises a question as to the aetiology and the molecular basis of such variation in the human ejaculate, toward which the following discussion is directed.

Neither the frequent occurrence of different morphological types of spermatozoa (see MacLeod, 1964) nor the qualitative heterogeneity of the nucleus discussed here-both essentially human phenomena-has been explained from an aetiological standpoint. It may be that a modification of scrotal temperature engendered by clothing worn in this society is a contributory factor, and a study of the ejaculated spermatozoa from men in other cultures where little is worn about the scrotal region would be of interest in this respect. Nuclear heterogeneity could result from variations at the molecular level in (a) protein synthesis, this being qualitative and/or quantitative, or (b) in the proportion of the available protein-bound thiol groups which eventually form crosslinks between the protein chains during passage through the epididymis. With regard to the first possibility, protamine extracted from the ejaculates quoted in Table 1 appears as a single electrophoretic band (H. Calvin, unpublished observations); this would seem to preclude other than rather minor differences in amino acid composition. Nothing is known of possible differences between nuclei in their total protein content. It is probable that in many cases, the heterogeneity revealed by SDS/DTT among nuclei of similar fine-structural appearance reflects differences in the proportion of the thiol groups which form -S-S- crosslinks between the nucleoprotein chains. We have investigated the possibility that free thiol groups are still available for crosslinking in some spermatozoa after ejaculation. This was effected by exposing them to the oxidizing influence of $10^{-3} \mathrm{M}-\mathrm{Cu}^{++}$for $1 \mathrm{hr}$. The nuclei of human sperm samples which appear most stable in SDS/DTT (e.g. Nos 21, 38 and 41 in Table 1) did not develop a further resistance to this medium after such exposure to $\mathrm{Cu}^{++}$. By contrast, samples which responded rapidly to SDS/DTT (e.g. Nos 3, 5 and 29 in Table 1) became significantly more resistant after similar exposure to $\mathrm{Cu}^{++}$, an indication of the initial presence of uncommitted thiol groups in the nucleus of many of these spermatozoa. It is possible that a differential rate of passage of individual spermatozoa from the rete testis to the ejaculate might contribute significantly to the subtle heterogeneity revealed by DTT. In the epididymis of animals, there is some variation in the rate of transport with mixing of spermatozoa of somewhat different ages (Koefoed-Johnson, 1960; Orgebin-Crist, 1962), those at the periphery of the duct tending to progress at a rather greater rate than those in the centre of the lumen (Orgebin-Crist, 1965). This mixing apparently occurs to a much greater degree in the human epididymis where there can be a striking variation in the rate of sperm passage within an individual; this ranges from 1 to 2 days to a maximum of 21 days, with a mean of about 12 days (Rowley, Teshima \& Heller, 1970). Gross difference between spermatozoa in the rate of epididymal transport might contribute significantly to within-sample heterogeneity of sperm nuclei, for the epididymal environment, while not necessary for establishment of disulphide links, seems to regulate the extent of such bonding (Calvin \& Bedford, 1971). 
We are aware of claims that subfertility may be correlated with a variable and/or diminished content of DNA in morphologically normal spermatozoa (Leuchtenberger, 1960; Jöel, 1962, 1971). It must be recognized, however, that the techniques used for such DNA measurements are not necessarily valid (Mann, 1964) and can be influenced by several factors other than DNA content. These include the protein composition of the chromatin, the state of condensation of the nucleus, and perhaps the degree of $-\mathrm{S}-\mathrm{S}-$ crosslinking, all of which may be pertinent to the present observations (Walker \& Richards, 1959; Gledhill et al., 1966a; Bouters, Esnault, Salisbury \& Ortavant, 1967; Calvin \& Bedford, 1971).

The present findings raise the difficult question of the extent of the spermrelated contribution to embryopathy in man. There are claims of a correlation between the incidence of abnormal morphology of human spermatozoa and spontaneous abortion (McBurney, 1954; Furuhjelm, Jonson \& Lagergren, 1962; Ballerio \& Giarola, 1962; Roszkowski \& Sroka, 1962; Jöel, 1962; Raboch, 1965), though others deny this (MacLeod \& Gold, 1957; Swyer, 1953; Hartman, 1965). The present study demonstrates, however, that even a normally shaped human sperm nucleus may often be abnormal at the molecular or the ultrastructural level. Moreover, genetic paternal defects are often expressed by early death of the embryo in the pre- or peri-implantation period (Bishop, 1964, 1970), an event which would not be detected in the course of normal clinical observation. Although the consequences of structural anomaly or immaturity of the nuclear chromatin in a fertilizing spermatozoon are not known, it is noteworthy that rabbit eggs fertilized by spermatozoa from the lower corpus and proximal caudal regions of the epididymis apparently achieve a significantly lower rate of implantation and successful postimplantation development (Orgebin-Crist, 1969). This could mean that the non-visible maturation changes involving establishment of -S-S- crosslinks in the sperm nucleus during epididymal passage (Calvin \& Bedford, 1971) have some bearing on the ability of the spermatozoon to support normal embryonic development. A report of abnormal binding of Feulgen and cationic dyes by the chromatin of normally shaped motile spermatozoa from a subfertile bull (Gledhill et al., 1966b) also provides suggestive evidence that the physical state of the nuclear chromatin may have a direct bearing on fertility. These considerations, the high incidence of spontaneous abortion in this society (15 to $20 \%$ of all pregnancies-WHO, 1970) and the possibility of a greater fetal loss at an earlier stage of human development (Hertig \& Rock, 1949) suggest that the subject of sperm-related embryonic pathology in man is worthy of further basic and clinical study.

\section{AGKNOWLEDGMENTS}

The spermatozoon shown in Pl. 3, Fig. 6 was present in the tubular lumen of a testicular biopsy kindly provided by Dr M. J. Rowley and Dr C. G. Heller. We thank Mrs Emelda Sanidad for her technical assistance. This work has been supported by N.I.H. Grants HD 03623 and HD 05316. 


\section{REFERENGES}

ALFERT, M. (1956) Chemical differentiation of nuclear proteins during spermatogenesis in salmon. $\mathcal{F}$. biophys. biochem. Cytol. 2, 109.

Ballerio, G. \& Giarola, A. (1962) Disformie nemaspermiche e aborti 'a ripetizione'. Annali Ostet. Ginec. 84, 911.

Bishop, M. W. H. (1964) The paternal contribution to embryonic death. 7. Reprod. Fert. 7, 383.

Bishop, M. W. H. (1970) Ageing and reproduction in the male. 7. Reprod. Fert. Suppl. 12, 65.

Bouters, R., Esnault, G., Salisbury, G. W. \& Ortavant, R. (1967) Discrepancies in analyses of deoxyribonucleic acid in rabbit spermatozoa, involving Feulgen staining (Feulgen-DNA) and ultraviolet light absorption (UV-DNA) measurements. F. Reprod. Fert. 14, 355.

Calvin, H. \& Bedford, J. M. (1971) Formation of disulphide bonds in the nucleus and accessory structures of mammalian spermatozoa during maturation in the epididymis. J. Reprod. Fert. Suppl. 13, 65.

Coelingh, J. P., Rozijn, T. H. \& Monfoort, C. H. (1969) Isolation and partial characterisation of a basic protein from bovine sperm heads. Biochim. biophys. Acta, 188, 353.

Eliasson, R. (1971) Standards in evaluation of human semen. Andrologie, 3, 49.

FAWCETT, D. W. (1958) The structure of the mammalian spermatozoon. Int. Rev. Cytol. 7, 195.

Fawcett, D. W., Anderson, W. A. \& Phillips, D. M. (1971) Morphogenetic factors influencing the shape of the sperm head. Devl Biol. 26, 220.

Fawcetr, D. W. \& Burgos, M. H. (1956) Observations on the cytomorphosis of the germinal and interstitial cells of the human testis. Ciba Fdn Colloq. Ageing, 2, 86.

FREUND, M. (1966) Standards for the rating of human sperm morphology: a cooperative study. Int. $\mathcal{F}$. Fert. Suppl. 11, 97.

Freund, M. (1968) Semen analysis. In: Progress in Infertility, p. 593. Eds. S. J. Behrman and R. W. Kistner. Little, Brown, Boston.

Furuhjelm, M., Jonson, B. \& Lagergren, C. G. (1962) The quality of human semen in spontaneous abortion. Int. F. Fert. 7, 17.

Gledhill, B. L., Gledhill, M. P., Rigler, R., Jr \& Ringertz, N. R. (1966a) Changes in deoxyribonucleoprotein during spermiogenesis in the bull. Expl Cell Res. 41, 652.

Gledhill, B. L., Gledhill, M. P., Rigler, R., JR \& Ringertz, N. R. (1966b) Atypical changes of deoxyribonucleoprotein during spermiogenesis associated with a case of infertility in the bull J. Reprod. Fert. 12, 575.

Hartman, G. G. (1965) Correlations among criteria of semen quality. Fert. Steril. 16, 632.

HeRTIG, A. T. \& Rock, J. (1949) A series of potentially abortive ova recovered from fertile women prior to the first missed menstrual period. Am. 7. Obstet. Gynec. 58, 968.

JöEL, G. A. (1962) Zur Aetiologie des habituellen Abortes unter Berücksichtigung des männlichen Faktors. Gynaecologia, 154, 257.

JöEL, G. A. (1971) Pathological semen as a factor in abortion and infertility. In: Fertility Disturbances in Men and Women, p. 496. Ed. C. A. Jöel. Karger, Basel.

Kozfoed-Johnson, H. H. (1960) Influence of ejaculation frequency on the time required for sperm formation and epididymal passage in the bull. Nature, Lond. 185, 49.

KopeCNY, V. (1970) Labelling of mouse spermatozoa with L-arginine ${ }^{14} \mathrm{C}(u)$ monohydrochloride. $Z$. Zellforsch. mikrosk. Anat. 109, 414.

LEUCHTENBERger, C. (1960) The relation of the desoxyribosenucleic acid (DNA) of sperm cells to fertility. F. Dairy Sci. Suppl. 43, 31.

LorR, M. (1970) Modification du contenu en arginine et en cystine des nucléoprotéines des spermatides allongées du bélier (Ovis aries). C. r. hebd. Séanc. Acad. Sci., Paris, 271, 1634.

McBurney, R. D. (1954) The male factor in sterility and abortions. West. F. Surg. Obstet. Gynec. 62, 295.

McCosker, P. J. (1969) Abnormal spermatozoan chromatin in infertile bulls. F. Reprod. Fert. 18, 363.

MACLEOD, J. (1964) Human seminal cytology as a sensitive indicator of the germinal epithelium. Int. F. Fert. 9, 281.

MACLEOD, J. (1970) The significance of deviations in human sperm morphology. In: The Human Testis, p. 481. Eds. E. Rosenberg and A. V. Paulsen. Plenum Press, New York and London.

MacLeod, J. \& Gold, R. Z. (1957) The male factor in fertility and infertility. IX. Semen quality in relation to accidents of pregnancy. Fert. Steril. 8, 36.

MANN, T. (1964) Biochemistry of semen and of the male reproductive tract, chap. VI. Methuen, London.

MONESI, V. (1965) Synthetic activities during spermatogenesis in the mouse: RNA and protein. Expl Cell Res. 39, 197.

Monesi, V. (1971) Chromosome activities during meiosis and spermiogenesis. F. Reprod. Fert. Suppl. 13, 1.

Orgebin-Crist, M. C. (1962) Recherches expérimentales sur la durée de passage des spermatozoïdes dans l'épididyme du taureau. Annls Biol. anim. Biochim. Biophys. 2, 51. 
Orgebin-Grist, M. C. (1965) Passage of spermatozoa labelled with thymidine- ${ }^{3} \mathrm{H}$ through the ductus epididymidis of the rabbit. F. Reprod. Fert. 10, 241.

Orgebin-Grist, M. C. (1969) Studies on the function of the epididymis, Biol. Reprod. Suppl, 1, 155.

RABOch, J. (1965) Spermiologische Befunde bei wiederholten Schawangerschaftsverlusten. Zentbl. Gynäk. 87, 194.

Roszxowski, I. \& SROKA, L. (1962) The effect of the male factor on abnormal pregnancy. Gynaecologia, $154,321$.

Rowley, M., Teshima, J. F. \& Heller, C. G. (1970) Duration of transit of spermatozoa through the human male ductular system. Fert. Steril. 21, 390.

Swyer, G. I. M. (1953) Discussion on male infertility. Proc. R. Soc. Med. 46, 385.

Vaughn, J. (1966) The relationship of the 'sphere chromatophile' to the fate of displaced histones following histone transition in rat spermiogenesis. F. Cell Biol. 31, 257.

WALKER, P. M. B. \& Richards, B. M. (1959) Quantitative microscopical techniques for single cells. In: The Gell. Biochemistry, Physiology, Morphology, Vol. I, p. 816. Eds. J. Brachet and A. Mirsky. Academic Press, New York.

WHO (1970) Spontaneous and induced abortion. Technical Report No. 461. 